\title{
EL RIO MAGDALENA EN EL CRECIMIENTO HISTORICO DE HONDA (COLOMBIA). Un caso atípico de morfología urbana en América latina
}

\author{
Juan José Ospina-Tascón. Doctor Arquitecto \\ Universidad del Tolima (Colombia) \\ jospina@ut.edu.co
}

\section{RESUMEN}

El municipio de Honda (Tolima - Colombia) se sitúa en la convergencia del río Grande de la Magdalena, Gualí y la quebrada Seca. Su localización geográfica constituye un nodo estructurante clave para el desarrollo regional en el contexto histórico colombiano. Honda desde su conformación se ha configurado de manera atípica a las demás ciudades latinoamericanas trazadas con la impronta del damero. El objetivo del estudio es reconocer la relevancia del río Grande de la Magdalena, sus afluentes y las condiciones geomorfológicas del lugar como elementos relevantes en su transformación urbana relacionada de manera estrecha con el entorno. Se indagan fuentes primarias, de archivo histórico, literatura y planimetría referente a procesos de poblamiento y colonización, que luego se contrasta con cartografía actual y fotografías satelitales que permiten aportar material gráfico y teórico nuevo que amplía la explicación de la actividad fluvial en el contexto histórico de Honda y su repercusión nacional.

Palabras clave: Honda, Río Magdalena, Centro histórico, Conservación.

\section{ABSTRACT}

The municipality of Honda (Tolima - Colombia) is located at the convergence of the Grande de la Magdalena River, Gualí and the Seca Stream. Its geographical location constitutes a key structuring node for regional development in the Colombian historical context. Since its formation, Honda has been configured in an atypical way to the other Latin American cities traced with the imprint of the checkerboard. The objective of the study is to recognize the relevance of the Grande de la Magdalena River, its tributaries and the geomorphological conditions of the place as relevant elements in its urban transformation closely related to the environment. Primary sources, historical archive, literature and planimetry referring to settlement and colonization processes are investigated, which is then contrasted with current cartography and satellite photographs that provide new graphic and theoretical material that expands the explanation of fluvial activity in the historical context of Honda and its national repercussion.

Key words: Honda, Magdalena River, Historic Center, Conservation. 


\section{INTRODUCCIÓN. AGUA Y CIUDAD}

El agua constituye un elemento geográfico que condiciona la organización espacial, el crecimiento y la actividad productiva de las ciudades (Whitehead, Smith \& Wade, 2011; Kostof, 2005). En este sentido, una constante universal en el desarrollo de las civilizaciones ha sido el permanente vínculo con un río principal, entendido como un elemento natural que hace posible la vida, contribuye a optimizar ámbitos tanto económico como urbano, cultural, social y por supuesto el hidrográfico.

Los ríos son elementos de gran interés paisajístico, por ello "sanear e invertir en los cuerpos de agua y sus entornos les da valor a las ciudades, aumentan la calidad de vida y proporcionan ambientes sanos" (Camacho, 2014). Es tal el vínculo que se establece entre el rio con la ciudad, que este resulta convirtiéndose en testigo de su historia urbana. El río se destaca como un elemento del paisaje que contribuye a generar identidad y apego a quienes habitan cerca de este (Duffo, 2013).

En Colombia el río Magdalena con una longitud de 1500 km, se constituye como el principal eje hídrico navegable desde Honda (Tolima) hasta su desembocadura en Bocas de Ceniza (Atlántico) en el mar caribe. El río Magdalena ha sido desde el inicio de la conquista española en 1536 hasta la actualidad, un elemento natural forjador de dinámicas que han contribuido a potenciar el desarrollo nacional.

El hombre, como ser social interactúa con sus semejantes en el medio natural y lo transforma para habitarlo, dominarlo y explotar sus recursos. Se ha evidenciado que desde la antigüedad, grandes civilizaciones como la griega y sumeria establecieron sus ciudades frente a bordes fluviales como estrategia militar, comercial, de intercambio y también de comunicación con otras comunidades o sitios de abastecimiento.

Esta reflexión nos lleva a deducir que la importancia del lugar que recorre el río Magdalena radica en su posición geográfica donde coinciden diversas rutas terrestres con el eje fluvial, lo que permitió la explotación e intercambio de productos, la conformación del inicial asentamiento y la consolidación del municipio como nodo relevante en la red de intercambios desde el periodo colonial, pues hacia el oriente del puerto se encontraba el altiplano y la población más numerosa del país, hacia el occidente se hallaban las provincias mineras de Cauca y Antioquia, todas estas importantes destinos para las mercancías que llegaban de España. Es por ello que Honda se convierte en el principal puerto del interior del país, ya que desde allí se distribuían los productos importados de España y los que se exportaban productos minerales y vegetales desde el interior del país y el norte del Tolima

El presente estudio se realiza con el propósito de aportar material gráfico que complemente la literatura histórica de Honda, puesto que tras una amplia consulta en fuentes literarias y en archivos documentales, los hallazgos describen de manera anecdótica sus puertos, edificaciones y personajes que intervinieron durante su transformación y consolidación urbana, pero no existe una planimetría exacta que complemente la teoría.

La metodología propuesta para el desarrollo de la investigación se centra en la reconstrucción grafica de cada uno de los momentos que han acontecido en Honda desde su conformación inicial hasta la actualidad con el propósito de identificar el papel que ha tenido el río Magdalena en este lugar, además de la repercusión en el comercio y la historia de Colombia. Este proceso se desarrolla mediante el redibujo urbano de Honda en AutoCAD durante cada uno de los momentos importantes en el crecimiento urbano, comparando planimetría urbana histórica y actual, fotografías aéreas, satelitales y la reinterpretación del lugar durante diversas visitas de campo.

\section{El papel del Rio Magdalena y sus afluentes en el contexto urbano-histórico de Honda}

En la zona norte del departamento del Tolima (Colombia) se ubica el municipio de Honda. Un lugar escarpado donde convergen las estribaciones de las cordilleras Oriental y Central, se constituye geográficamente como una "península", debido a que está acompañado de agua en tres de sus lados por ríos. El principal es el Magdalena, que forma una curva pronunciada donde convergen los ríos Gualí y Quebradaseca. Dicho escenario geográfico que tiene unas características topográficas singulares acogió a los primeros habitantes de un territorio donde se desarrolló una transformación urbana particular durante su primer asentamiento, la conformación como Villa y luego como ciudad.

En Colombia, el rio Magdalena constituye una referencia vertebral de las manifestaciones culturales de las ciudades fundadas en sus orillas (Honda, Ambalema, Mariquita, en el caso del departamento del Tolima), y de los habitantes de sus riberas, de acuerdo con una relación simbiótica con el Rio y el resultado de la adaptación al medio. 


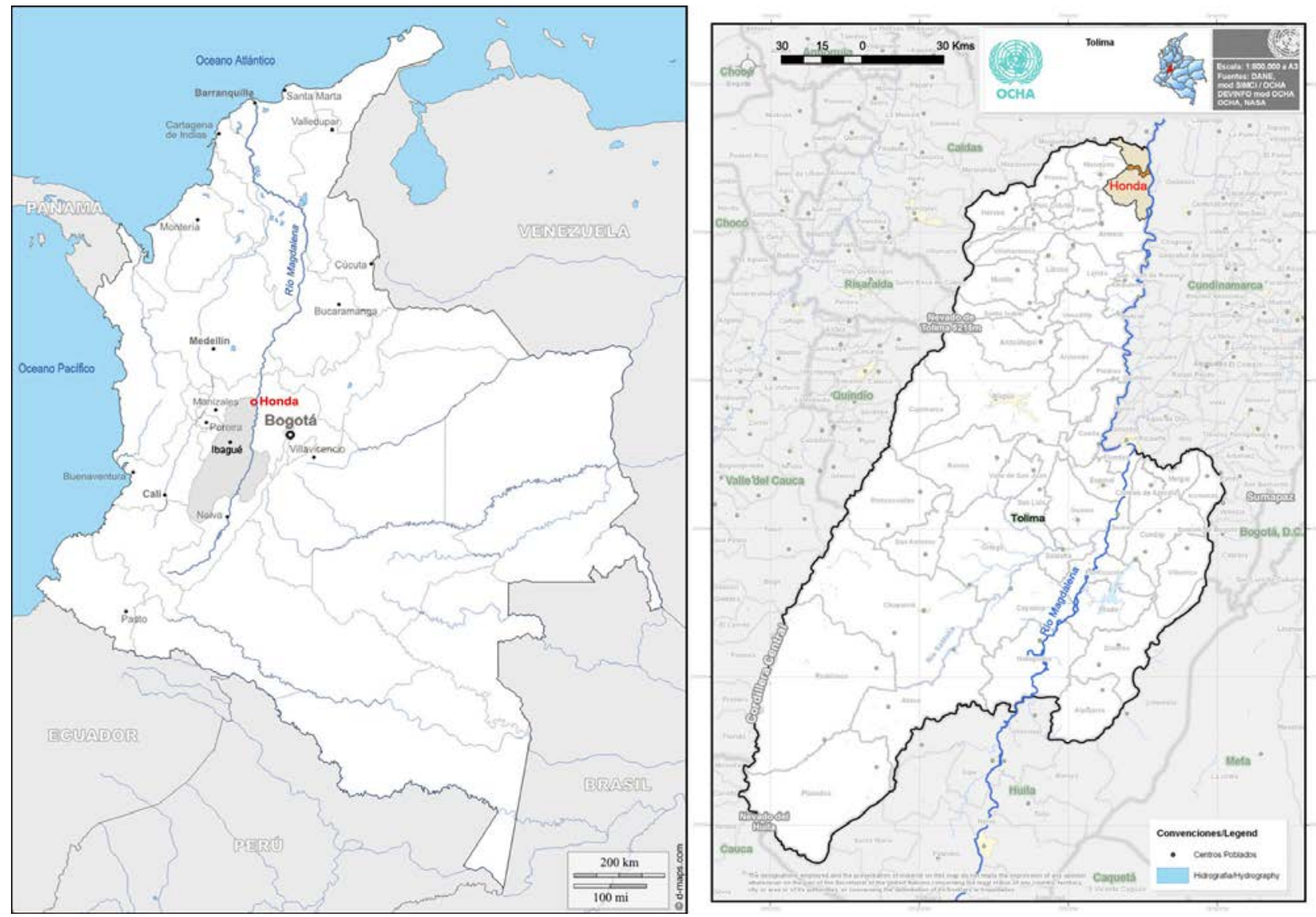

Ilustración 1. Localización de Honda respecto al río Magdalena. Mapa de Colombia y del departamento del Tolima.

Fuente: Elaboración propia a partir de planimetría obtenida del Instituto Cartográfico Agustín Codazzi y OCHA.

\section{Diagrama No. 1}

\section{Perfil esquemático del río Magdalena}

(Eje de las ordenadas: altitud -msnm; y eje de las abscisas: longitud - km)

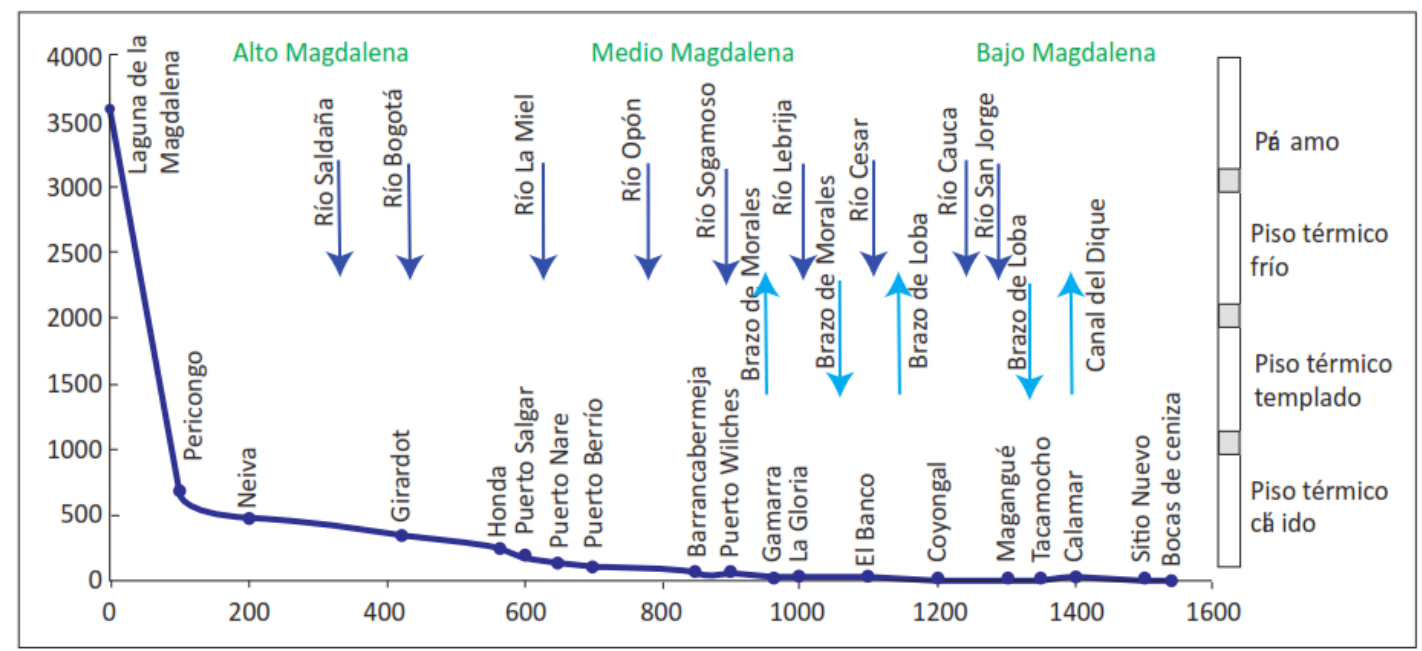

\section{Distancia en kilómetros}

Fuente: Tomado del Atlas Cuenca Río Magdalena, 2002.

llustración 2. Perfil esquemático del río Magdalena. (Eje de las ordenadas: Altitud, msnm y eje de las abcisas: Longitud: km). Fuente: Atlas - Cuenca del río Magdalena, 2002. 
La geografía de la ciudad es inseparable de su historia y sin ambas no podemos comprender su arquitectura, la huella concreta de esa "cosa humana" (Rossi, 2015). La topografía accidentada del lugar donde se emplaza el municipio de Honda ha repercutido de manera significativa en la actual configuración urbana. Esto se puede deducir al analizar su surgimiento espontáneo sin acto fundacional y el crecimiento urbano que debió adaptarse a la topografía escarpada que existe entre las cuencas del río Gualí y la quebrada Seca en contraste con la planicie que constituye el territorio de Mariquita.

La cercanía de Honda al río Magdalena y su localización geográfica en el centro del país, contribuyeron a que se convirtiera en un enclave económico para Colombia. En la ribera occidental del río Magdalena existe un corte de terreno vertical de unos treinta metros de altura sobre el nivel del río, que hace posible el dominio visual para controlar el paso de oriente a occidente por tierra mediante el uso de puentes que permitieran el intercambio de mercancías y de norte a sur de manera fluvial. Allí se encuentran dos importantes ejes hídricos que han condicionado la morfología urbana de Honda: primero, el Gualí, que nace en el páramo de Herveo en la cordillera Central, es un río con abundantes piedras, angosto y corrientoso que desemboca en el Magdalena. Segundo, la quebrada Seca.

Como lo explica Guzmán (2002), la historia de Honda se desarrolla de manera simultánea a los usos que el hombre le ha dado al río Magdalena, "desde la conformación espontánea como embarcadero hasta el momento en que pasó a convertirse en el puerto fluvial más importante para las provincias andinas a lo largo de cuatro siglos hasta cuando la navegación fluvial fue sustituida por otros medios de transporte terrestre".

El río Magdalena se constituyó como la ruta principal para la navegación en el Nuevo Reino de Granada y por lo tanto, el eje estructurante del intercambio y comunicaciones en el Nuevo Reino mediante la utilización de canoas de origen indígena. Sin embargo, en repetidas ocasiones la corona prohibió este sistema ante la notable disminución de esta población causada por ese duro trabajo. Desde 1590 se introdujo la mano de obra esclava para reemplazar a los indios. El tramo navegable desde honda hasta Mompox vinculaba el centro y norte del país otras partes del territorio y Honda fue el nodo donde convergían caminos y vías importantes para el funcionamiento del Nuevo Reino, esto posibilitó el abasto de las ciudades y explotación de las minas, generándose nuevos procesos de poblamiento y usos del suelo.

El origen de la Villa además del Magdalena involucró al río Gualí donde se ubicó el puente de San Francisco y otro construido en la segunda mitad del siglo XVIII. Estos puentes fueron prolongaciones de las calles que unieron los dos sectores de la Villa y que facilitaron la relación de distribución del puerto con las ciudades de Mariquita, Ibagué y más allá, con el occidente del territorio.

La historia urbana de Honda, durante este siglo, está impregnada de daños en los puentes por causa de las diferentes crecientes del río Gualí a lo largo del siglo XVIII $(1710,1744,1750,1757,1762,1771)$ que evidenciaron la existencia de talleres y oficios especializados en la Villa como carpinteros, alarifes y herreros. El río Gualí y la quebrada Seca, aunque menor en longitud y caudal, también fueron y continúan siendo elementos fundamentales en la configuración urbana de Honda. En esta convergencia de ríos la geomorfología del lugar es particular, pues se precipita sobre peñascos pedregosos que convierten sus aguas en cursos torrentosos. Este nodo en la actualidad recibe el nombre del Salto de Honda.

\subsection{El papel del agua y la topografía en la configuración urbana atípica de Honda}

Desde de la conquista de América a finales del siglo XV, numerosas ciudades fundadas por los españoles se gestaron mediante la implementación del damero. Un diseño espacial común que propone una traza urbana reticular de calles y manzanas en las que se replicaba el modelo tipológico propio de ciudades europeas bajo el dominio cristiano (Morris, 2011). Este patrón se desarrolló alrededor de una plaza donde se ubican edificios de índole gubernamental, eclesiástico, civil y económico propia de otros centros históricos que existen en numerosas ciudades latinoamericanas fundadas, tales como, Tunja, Popayán, Lima y Quito.

Como lo explica Guzmán (2002), este modelo además de garantizar orden y control en las nuevas ciudades, posibilitaba a los españoles protegerse de un medio desconocido y hostil. El damero fue propuesto en la antigüedad por el imperio romano como estrategia defensiva y de control, pero además como elemento de diseño que contribuiría a la organización territorial de las nuevas ciudades y la vinculación de los diversos usos del suelo, destacándose además la perspectiva y la escala monumental. 

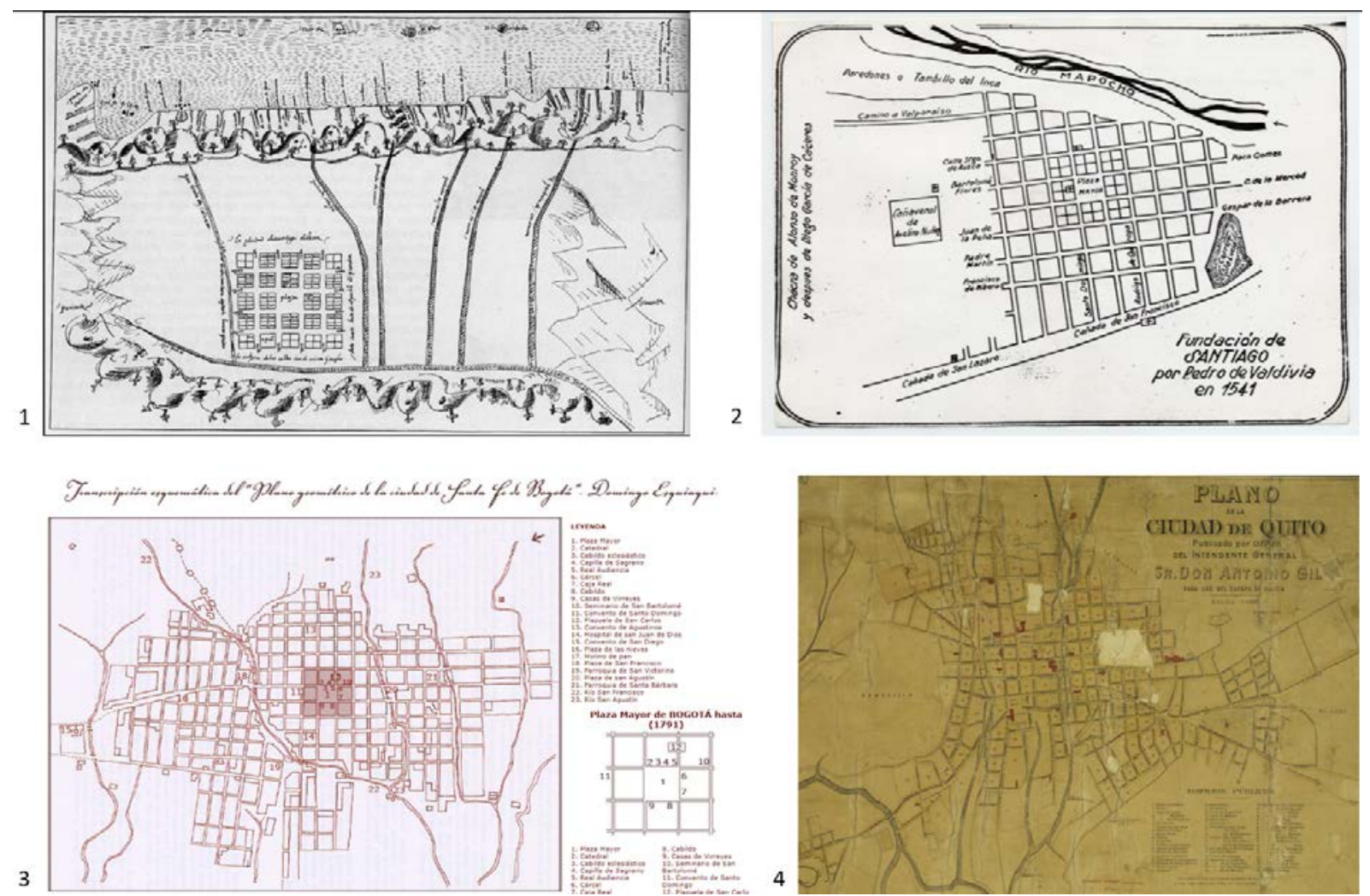

Ilustración 3. Dameros en Latinoamérica: 1. Caracas en 1578, 2. Santiago de Chile en 1541. 3. Santa Fe de Bogotá en 1791, 4. Quito en 1914. Fuente: 1. (De Sola, 1967) 2. Biblioteca Nacional de Chile 3. http://cartografia.bogotaendocumentos.com/mapa 4. http://repositorio.casadelacultura.gob.ec/bitstream/34000/17626/1/C097.jpg

En Colombia, el río Magdalena como eje navegable por su caudal y longitud garantiza la fertilidad del suelo a lo largo de la accidentada cordillera central. Este río fue elemento fundamental en la toma de decisiones por parte de los conquistadores respecto a la selección del lugar para nuevas fundaciones. (Zambrano \& Bernard, 1993). Sin embargo, desarrollar el modelo del damero en las condiciones irregulares del terreno en donde se hoy sitúa Honda fue complicado.

Al indagar en la conformación del primer asentamiento, se encuentra la referencia de Honda como un puerto descubierto en el año 1539 por tres reconocidos expedicionarios españoles. Entre ellos Gonzalo Jiménez de Quesada, Sebastián de Belalcázar y Nicolás de Federmann. En su recorrido por el Magdalena descubrieron un poblado de numerosos bohíos habitados por indígenas Ondamas, que pertenecían a la gran tribu Panche justo en la convergencia con el río Gualí.

La ocupación del Nuevo Reino como lo señala Colmenares (1972), se basa en los accidentes geográficos como elementos que permiten constituir nuevas fronteras territoriales. La conquista del territorio obedece también a la necesidad de controlar espacios vacíos, todavía no incorporados al dominio español, por medio del proceso de poblamiento. (Guzmán, 2002). Como era común en el territorio colombiano, la localización de asentamientos fue determinada por la de los recursos naturales. La presencia de metales preciosos también dio lugar a dos diferentes formas de ocupación del territorio. En este sentido, con la extracción del oro del río se formaron campamentos dando origen a los conocidos "Reales de minas".

El origen espontaneo del nuevo asentamiento dio como resultado una formación urbana atípica. En este caso, la configuración carecía de un lugar central compuesto por la plaza mayor y enmarcado por iglesia, conventos y cabildo, elementos comunes del modelo ortogonal. La topografía y los accidentes geográficos (los ríos, etc.), constituyeron barreras naturales que dieron como resultado calles ceñidas a las curvas de nivel, semejantes a las ciudades medievales. La vinculación al río en un territorio escarpado sirvió también como estrategia militar en cuanto a la protección del lugar durante la época de la conquista y dieron origen a la conformación de calles sinuosas y cuestas que aún se evidencian, siendo la calle de las Trampas la más reconocida.

Al finalizar el siglo XVI el proceso de poblamiento de la región continuó en desarrollándose de forma precaria debido a la fuerte resistencia indígena. La población urbana no aumentó en forma considerable; inclusive existe un relativo despoblamiento. La sociedad colonial se asentaba y comenzaba a modelar el espacio dependiente de cada una de las ciudades, no sólo desde el punto de vista del poblamiento aglomerado sino en lo referente a la economía de carácter agrario y de grandes propiedades (Guzmán, 2002). 
La ruta por el río Magdalena empieza a consolidarse rápidamente como vía natural para el intercambio entre el altiplano y el resto de las regiones. Por otra parte, con el inicio de la explotación minera de la región de Mariquita, Honda se convirtió en el desembarcadero de esta ciudad. Luego de su descubrimiento fue dada como tierra de encomiendas a Gonzalo Jiménez de Quesada, debido a la conectividad que existe con San Sebastián de Mariquita, que ya era una población importante, pero Honda estaba estratégicamente ubicada debido a la cercanía al río.

En el año de 1560 aproximadamente, la vinculación del inicial asentamiento con el río Magdalena continuaba siendo directa. En este periodo, pasó a ser parroquia de blancos cuando se da el proceso de fundación, aunque no existe un documento que lo evidencie. Honda obtiene el "Titulo de Villa de San Bartolomé de Honda", certificado mediante Real Cédula el 4 de marzo de 1643. (Ocampo, 1984). Lo que se reconocía como un poblado de categoría inferior a la de ciudad.

En este periodo se conformó el hospicio de San Francisco (Actual plaza de mercado), y residencia de la Compañía de Jesús (Florez de Ocariz, 1674). A pesar de su escala urbana, el papel de Honda en el crecimiento económico del país fue relevante, ya que se consolidó como un hito nacional y fue la Villa más importante del Virreinato, considerado además como el puerto interno de la ciudad de Cartagena debido a la relación directa con el río Magdalena y los caminos reales.

En el periodo de la republica (1835-1853), Honda fue centro de aprovisionamiento del norte del país y de intercambio internacional, principalmente con Inglaterra. Como puerto, fue escala obligada y se constituyó como el principal nodo fluvial mediante el uso de navegación a vapor en el río Magdalena en donde se intercambiaba y comerciaba plata, tabaco, café, quina, añil y demás productos y fue punto estratégico durante las guerras civiles.

Durante la Colonia fue considerada la "Garganta del Virreinato", es decir, su principal puerto interior y llave de las comunicaciones. Su crecimiento urbano y económico era el resultado de la vinculación directa con el río Magdalena, pero su trazado urbano difería de las típicas ciudades latinoamericanas pues no correspondía al modelo colonial, ya que se ubicaba en un terreno escarpado y subdividido por el río Gualí, que converge de manera perpendicular al Magdalena y aunque posee menor caudal pasó a convertirse en un elemento urbano relevante, donde fue necesario construir puentes que dieran continuidad a las sendas terrestres denominadas "Caminos Reales", que comunicaban el resto del país.

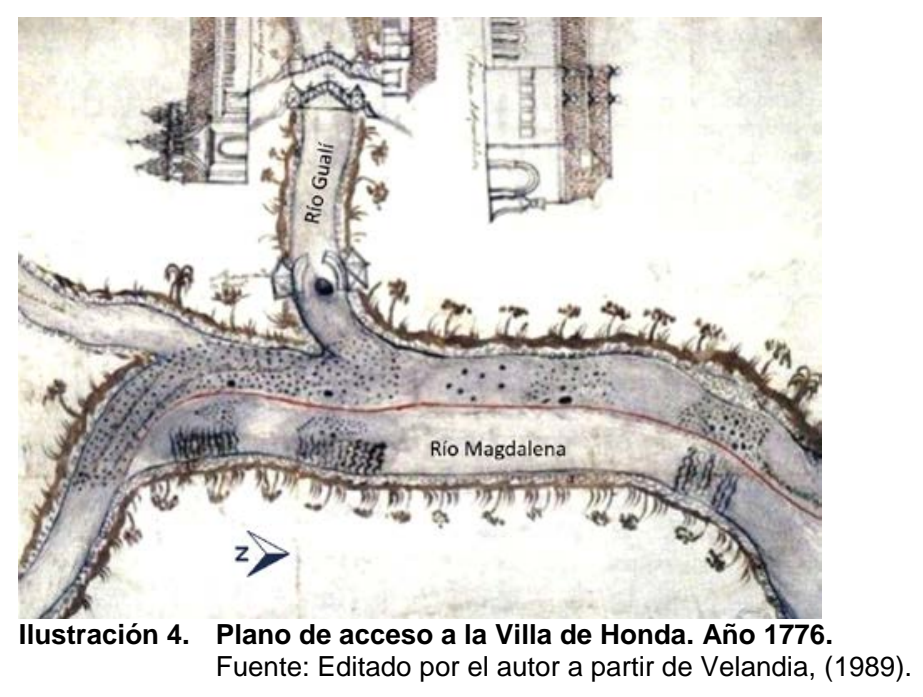

Honda se consolidó en el siglo XVII como un centro importante de intercambio debido a la conectividad directa con Santafé, Ibagué, Cartago, Popayán y Quito, por lo que su carácter comercial conllevo a la construcción de nuevos equipamientos especializados como bodegas, tiendas y hospedajes, por lo que fue preciso adecuar el terreno y proteger el sitio de las crecientes del río. Fueron puestas en servicio al finalizar el año (Archivo General de la Nación, 1741).

El crecimiento y la dinámica de construcción del espacio urbano de la Villa estuvieron directamente relacionados con el uso comercial. Las viviendas, a menudo de dos pisos, tenían sus respectivas tiendas. Ciertas calles como la Real, la del Comercio, la plazoleta del Convento de San Francisco y en forma tardía los sectores del Alto del Rosario se especializaron para el comercio. 
La población mestiza representa una proporción considerable del total. Sin embargo, la población española era la que poseía el poder económico y político como en el resto de ciudades y Villas. También se ha constatado que para esta época al consolidarse como Villa era necesario el nombramiento de un alcalde ordinario, un cabildo establecido, sede administrativa (ubicada en donde hoy existe la alcaldía), la casa consistorial, además de horca, picota publica, cárcel, a la implementación.

Durante el siglo XVII se localiza en la ciudad la orden religiosa de los Agustinos en los extramuros de la ciudad; por la misma época, se estableció la comunidad de Santo Domingo. Estos elementos religiosos, se reforzaron con la presencia de la Iglesia del Alto del Rosario y de la Parroquial hoy del Carmen. Para 1620, la Compañía de Jesús se estableció en el puerto y desde 1625 tuvo un reconocimiento eclesiástico al adjudicar la parroquia a los Jesuitas.
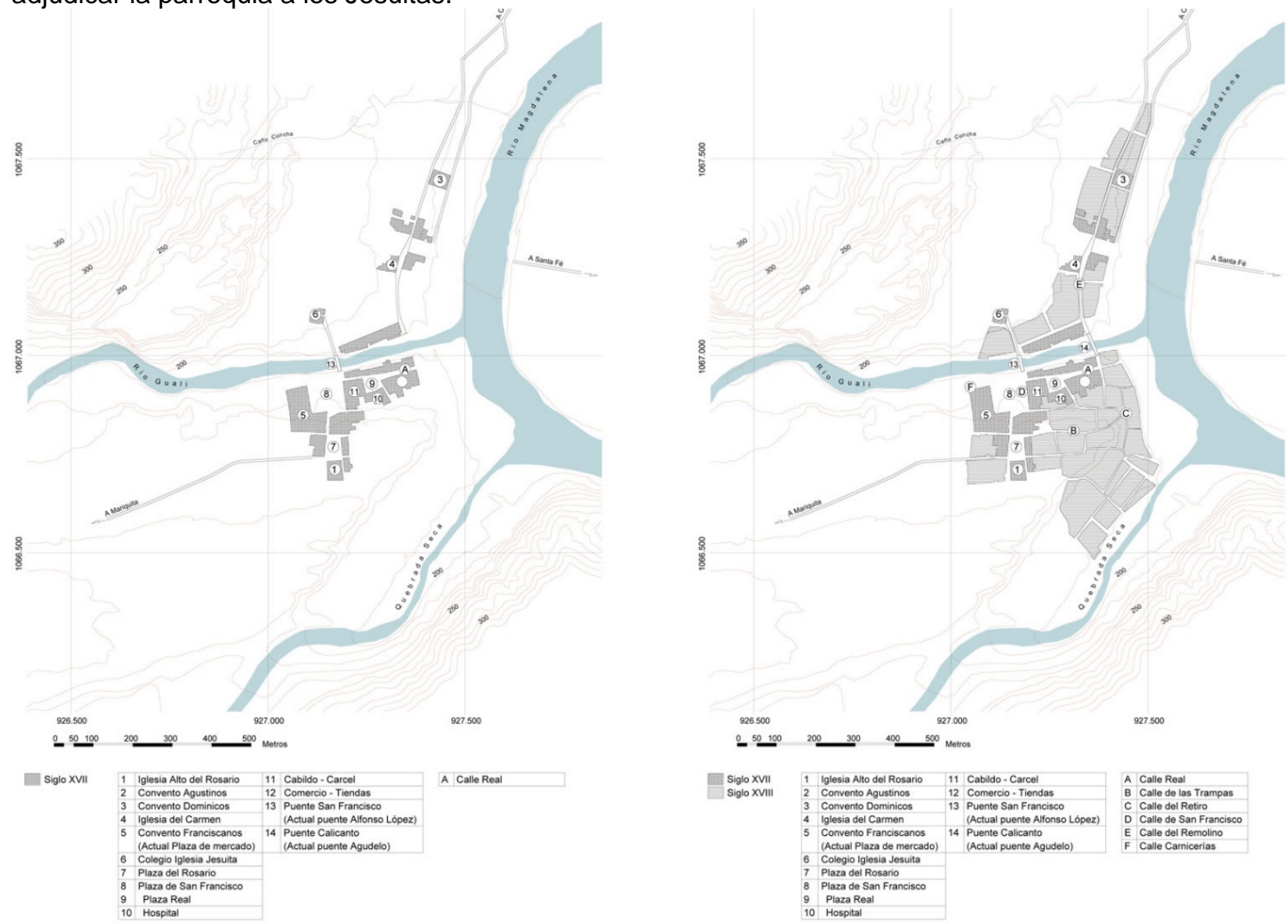

Ilustración 5. Crecimiento urbano de Honda durante los siglos XVII y XVIII. campo.

Fuente: Elaborado por el autor a partir de (Guzmán, 2002), fotografías satelitales obtenidas de Google Earth y visitas de

Como se explicó anteriormente, el territorio fue ocupado antes de la conquista por las tribus Panche y Pijao. Los Pijaos fue uno de los grupos Indígenas más rebeldes al dominio español que fue derrotado al igual que los demás grupos pequeños. Luego, hacia 1610 se continuó el mestizaje étnico y surgió entonces un poblamiento disperso, propiciado por las varias unidades de producción agrícola y minera, pero también concentraciones urbanas, asentamientos de crecimiento lento y complejo origen como es el caso de Honda, donde las condiciones naturales dificultaron ciertamente la implementación del trazado reticular y ordenado de las calles y manzanas, dispuestas alrededor de una plaza de forma cuadrada donde se ubican a su alrededor edificios de índole gubernamental, eclesiástico, civil y económico propia de otros centros históricos que existen en numerosas ciudades latinoamericanas fundadas como polo de dominio de interiores rurales, tales como, Tunja, Popayán, Lima y Quito.

En contraste, los múltiples desniveles del terreno propios del lugar, sirvieron como estrategia militar en cuanto a la protección del lugar durante la época de la conquista y dieron origen a la conformación de calles sinuosas que en la actualidad se evidencian, siendo la calle de las Trampas la más reconocida y las cuestas que aún se conservan como calles fueron lugar de vigilancia ante posibles asedios. En este sentido, analizar el crecimiento urbano de Honda permite comprender su continuo proceso de adaptación formal al territorio, pues 
se desarrolla como evidencia de múltiples sucesos vinculados al comercio e intercambio de productos, donde el río Magdalena es la senda principal de comunicación y la topografía del lugar el elemento que generó las pautas para el trazado único de sus calles.

\subsection{La higiene en la Villa de Honda}

La higiene urbana inicia en Latinoamérica en el siglo XVIII. Luego, con la influencia del Siglo de las luces el higienismo se hace importante en las colonias. Las ideas de la llustración tenían que ver con diferentes aspectos, entre ellos estaba el interés por el estudio espacial del problema sanitario, produciéndose entonces un incremento notable de las topografías médicas como metodología empleada para detectar los focos potencialmente malsanos y tratar con los medios disponibles para disminuir la morbilidad ciudadana causada por zonas urbanas que actúan como focos epidémicos, tomando desde entonces el espacio y el medio geográfico como objeto de estudio

La gestión residual de la ciudad contemporánea o los conceptos de sociedad urbana limpia y decente ya eran utilizadas por el Barón de Haussmann, en París y el estudio de Edwin Chadwick, en Londres (Urteaga, 1980; Ospina-Tascón, 2014). La Corona española consideraba que la riqueza de las naciones estaba basada en la abundancia de la población, por lo tanto las causas del despoblamiento serán una de las preocupaciones de los gobernantes. Las mejoras urbanas continúan y la medicina conoce adelantos acompañados de la noción de higiene: la comida, el buen aire, el aseo.

Nace una concepción de ciudad con calles amplias y limpias en las que circule el aire y con lugares donde depositar las basuras los muladares. El alcantarillado que hasta ese momento era un caño abierto, se cubre. Hasta entonces los muertos se enterraban en las iglesias o en el mejor de los casos, en un solar inmediato. Carlos IV se ocupó de este problema por Real Cedula del 27 de marzo de 1789 ordenando la construcción de cementerios en la perifería de las poblaciones. Estas ideas se realizaron mediante las orientaciones de le virreyes. (Guzmán, 2002)

\subsection{Conformación de barrios y usos del suelo en Honda. Siglos XVIII - XX}

La comercialización del tabaco y el establecimiento en Honda en 1778 de la Administración de renta del mismo, conllevó a un incremento en el intercambio comercial con las ciudades de la costa Atlántica y las del alto Magdalena, convirtiéndose el Puerto de Honda en el principal distribuidor de productos en el país. La actividad comercial conllevó a la consolidación de la ciudad y la zonificación de los usos del suelo. En el caso residencial se reporta la existencia de tres barrios desde el año: El de la Santa Iglesia o del Remolino; El del retiro y el del Alto del Rosario.

En el siglo XIX el suelo destinado a equipamientos religiosos y educativos también se definió. Los conventos de la Orden de San Francisco, el colegio de la Compañía de Jesús, el convento de la Popa y el de los Dominicos estaban en la Villa, algunos desde antes de su erección y otros casi inmediatamente. Estos elementos se ampliaron e inclusive cambiaron de lugar, como fue el caso del colegio de la Compañía de Jesús, localizado a una cuadra del casco urbano y que fue comprado por el Cabildo de Honda en 1769. Dos años después comenzó a funcionar como hospital y el terreno contiguo, como cementerio ${ }^{1}$. El colegio sólo pudo ser trasladado a la nueva construcción en 1765, dos años antes de la expulsión de los jesuitas del territorio.

Los primeros cinco años del siglo XIX mostraron síntomas de un relativo estancamiento del puerto. Nuevas rutas y puertos estaban en servicio. La importancia de Honda había menguado, los productos se distribuían a partir de otras rutas. El golpe fatal lo constituyó el terremoto de 1805, que arrasó con buena parte de su espacio urbano. Este período fatal duró hasta más o menos la mitad del siglo XIX, cuando la estabilización de la navegación por el río Magdalena impulsó un nuevo auge del puerto.

Con el terremoto de 1805 que derribo la casi totalidad de sus construcciones, la apertura de nuevos caminos y rutas comerciales, las guerras de independencia; la ciudad no solo se arruina sino pierde su importancia comercial. Después de la catástrofe, la ciudad inicia un lento proceso de recuperación hasta la segunda mitad del siglo XIX; con la introducción de la navegación a vapor por río Magdalena en 1847 y posteriormente en 1883 con la construcción del ferrocarril que uniera los dos puertos periféricos de la ciudad "Caracolí y Arrancaplumas", Honda despega de su decadencia, convirtiéndose en el eje principal de la economía y comercio del país.

\footnotetext{
${ }^{1}$ AGN, Fondo Hospitales y Cementerios, Torno III, folios 55-58.
} 
La Villa de San Bartolomé de Honda consolidó su importancia como puerto fluvial durante los periodos de Independencia (1810) y Gran Colombia (1819-1830). Como lo explica Guzman (2002), lo fue igualmente como posición estratégica en el movimiento de los ejércitos patriotas y realistas, que desde un comienzo pugnaron por su posesión, pudiendo decirse que quien ocupara esta plaza se hacía al dominio de la capital, pues Honda fue cuartel de la Independencia; allí se formó uno de los batallones que combatieron en el Bajo Magdalena en 1812. Allí los ejércitos se aprovisionaban de comida y embarcaciones, que acondicionaban para la guerra, formando con ellos "flotas" de combate. En 1815 pasa a ser ciudad, cuatro años más adelante se desarrolla en Colombia el proceso de independencia hasta 1819 y se potencia la economía por el auge del uso portuario del río Magdalena en los sitios denominados los Altos y los Bajos.

En el año de 1889 los dos márgenes del río Magdalena se unieron mediante la construcción del puente de hierro por el señor Bernardo Navarro, produciendo una importancia apreciable para el uso comercial de la ciudad. Años después se conforma la Plaza de Mercado, Iniciada en 1917, declarada en la actualidad Monumento Nacional, como también lo son El puente Navarro, el Centro histórico de la ciudad y su área de influencia.
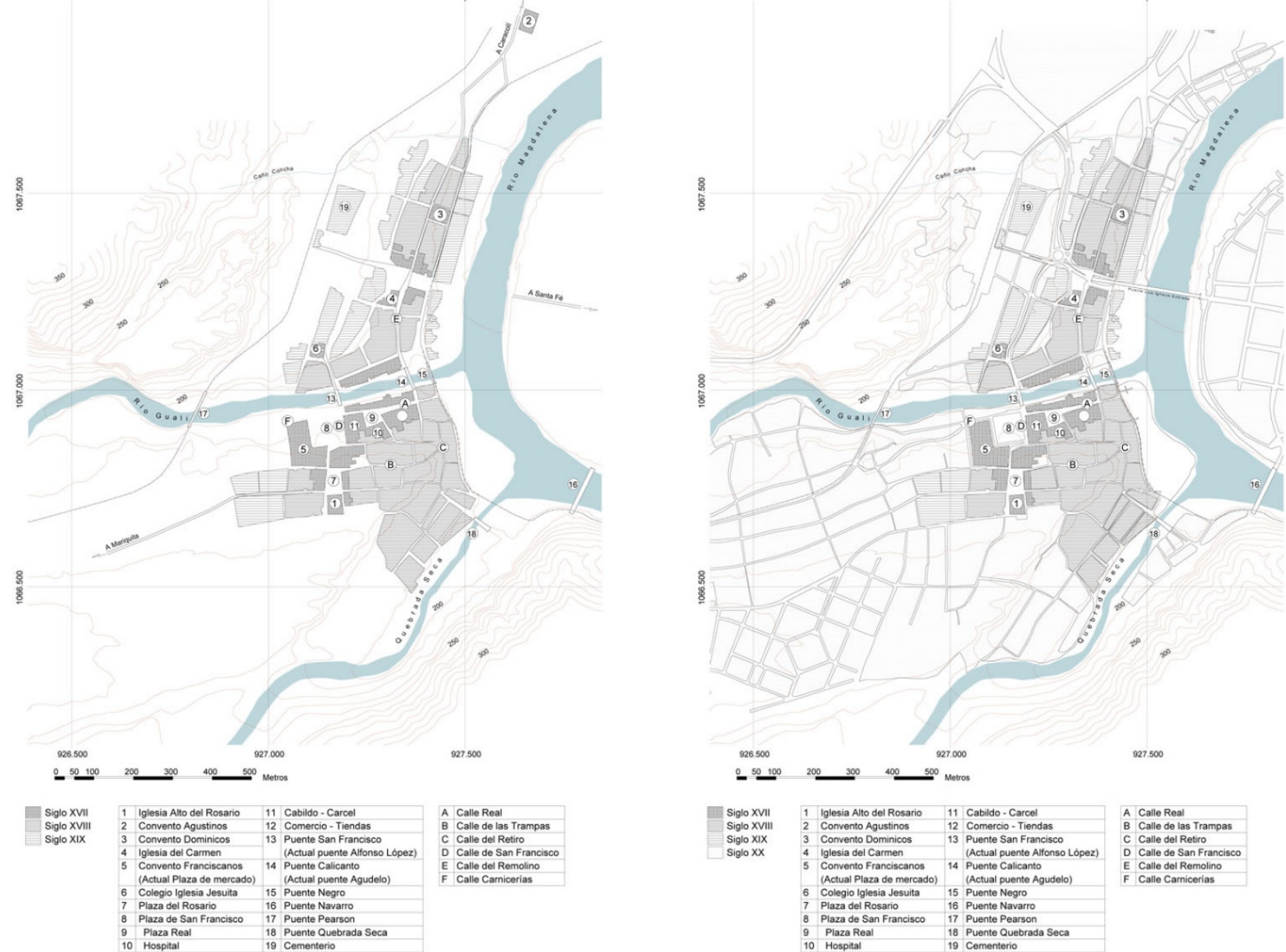

Ilustración 6. La geomorfología, el río grande de la Magdalena y sus vertientes como configuradores del crecimiento urbano de Honda. Siglos XIX y XX. Elaborado por el autor a partir del Mapa del Archivo General de la Nación: Fondo, Miscelánea, Tomos CVIII y CXXIX; Hospitales y Cementerios, Tomo III; Mejoras Materiales, Tomo XXI., fotografías satelitales obtenidas de Google Earth y visitas de campo.

El auge de Honda se relaciona en cada periodo histórico con la actividad portuaria y culmina con la incorporación del ferrocarril en Colombia, pues termina la navegación y Honda empieza a perder relevancia respecto a las ciudades que van creciendo y cobrando representación nacional. Este aspecto es seguramente un detonante en la evolución de la forma urbana tras aparecer nuevos usos del suelo, pues se evidencia que la inicial ciudad que antes radiaba respecto al río es ahora conocido como el centro histórico y es allí donde aún se mantiene la arquitectura tradicional colonial de Honda. Es tal el grado de conservación de las calles y edificaciones en el centro histórico que en el año 2010 Honda en general es declarado como Pueblo Patrimonio de Colombia. Allí se conservan la Catedral de Nuestra Señora del Rosario (1620), la calle de las Trampas, el Puente Navarro (Declarado en 1994), la Casa del expresidente Alfonso Lopez y la plaza de mercado (Partenon del Tolima, declarada en el año 1997). En la actualidad la ciudad es bautizada como la Cartagena del interior, Honda la ciudad de los puentes, Ciudad de la paz y como Ciudad de gente amable. 

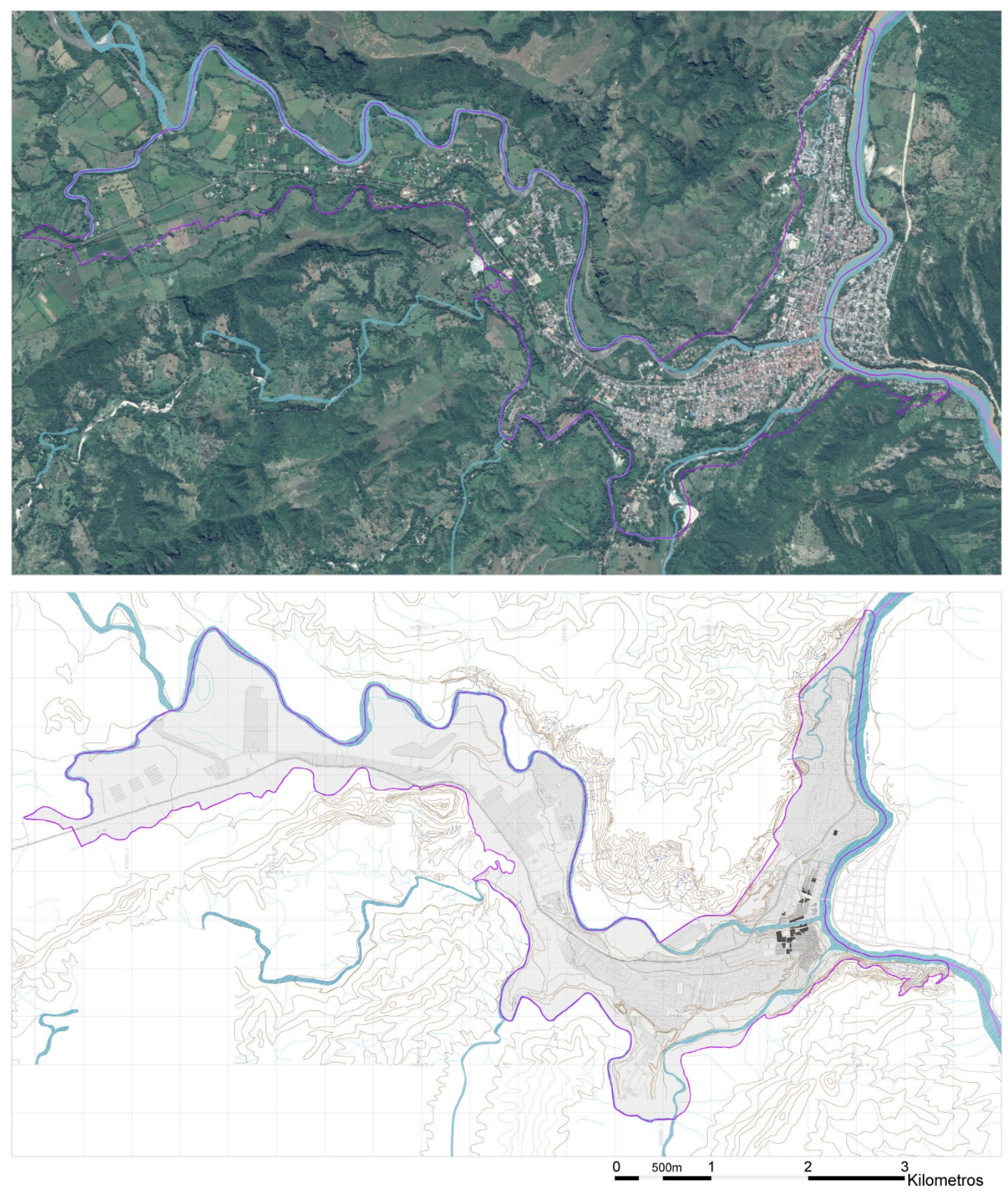

llustración 7. Morfología actual de Honda y su vinculación al Río Magdalena, la geomorfología y la vía férrea. Fuente: Elaborado por el autor a partir de indagación teórica y planimetrica de archivo, comparado con planimetría actual en formato CAD.

Honda, por su estrecho vínculo al río Magdalena continúa siendo reconocido por su papel en el crecimiento de Colombia. Pues la navegación contribuyó al intercambio económico pero también el cultural hasta cuando se acabó la navegación. En la actualidad es una ciudad donde se destaca su arquitectura y lenguaje de ciudad colonial como testimonio de su pasado que se evidencia en las fachadas de casonas señoriales de estilo andaluz y castellano que refleja la influencia cultural de sus colonizadores y quienes la han habitado hasta la actualidad. Como se mencionó anteriormente, Honda se reconoce como la "Ciudad de los puentes", Sin embargo, de los cuarenta construidos han desaparecido veintidós y tan solo se conservan dieciocho, contando los ubicados- sobre los ríos y quebradas que hacen parte del sector urbano y rural del municipio. 
Sin embargo, se considera necesario continuar preservando el patrimonio del municipio y sus bienes inmuebles e implementar estrategias que conlleven a conservar y preservar el Centro Histórico de Honda como un bien colectivo, sostenible y competitivo, como lo plantea el actual Plan Especial de Manejo y Protección (PEMP) de Honda (Ministerio de Cultura, 2017).

\section{CONCLUSIONES}

El Municipio de Honda, por su historia vinculada al río Magdalena continúa siendo un referente significativo en la historia nacional, como punto de intercambio comercial, pero además constituye para los tolimenses como uno de sus legados culturales de interés. Honda participó en el proceso formativo de la nacionalidad y en la Independencia de Colombia.

La geomorfología del lugar donde se emplaza el municipio de Honda ha repercutido de manera significativa en actual configuración urbana. Esto se puede deducir al analizar su surgimiento espontáneo sin acto fundacional y el crecimiento urbano que debió adaptarse a la topografía escarpada que existe entre las cuencas del río Gualí y la quebrada Seca en contraste con la planicie que constituye el territorio de Mariquita.

Se destaca la posición estratégica donde se ubica, respecto al cruce de caminos y el río Magdalena, principal senda de navegación. La "Villa de San Bartolomé de Honda", como se la nombraba en el lenguaje señorial de esa época, fue la más importante del virreinato y se tituló el pueblo del Puerto de Honda al ser erigido en tal calidad, nacida como embarcadero en la orilla del Río Grande de la Magdalena y su confluencia con el Gualí, sitio que vino a' ser el puente para ir del Nuevo Reino a España y para venir de allá a este, y también a Quito y el Perú en aquellos primeros años en que los de Santa Marta y Coro creían que por aquí quedaba aquel reino fabuloso y se podía ir hasta él.

Honda, por su historia y por la manera en que conserva su traza urbana adaptada a la convergencia de los ríos y la topografía propia del siglo XVII, periodo en que se consolidó como Villa del Nuevo Reino de Granada, es considerada como una expresión de hispanidad de la época en que España conquistó y colonizó el Nuevo Mundo, fundó ciudades.

Por Honda pasó y tuvo escala mayor el comercio de diversas materias primas Por Honda salió la plata y el oro de las minas del Reino; allí tuvo una base la Expedición botánica, allí pasaron las guerras civiles dejaron su rastro de heroísmo, y aparte de la Gran Colombia y durante todo el siglo XIX casi todos los grandes hombres que llegaron al país, quienes algo tuvieron que haber dejado y algo se llevaron.

Con el propósito de conservar el valor patrimonial del municipio, se hace necesaria la implementación de estrategias urbanas que contribuyan a vincular de nuevo la ciudad al río, espacios públicos que vinculen el entorno natural y articulen espacialmente las edificaciones vecinas, de las que un gran número por su edad, materialidad y estilo arquitectónico están catalogadas como bienes inmuebles de interés cultural en consonancia con los demás propósitos plasmados en el actual Plan Básico de Ordenamiento Territorial (PBOT) del municipio, pues La preservación del patrimonio contribuye en la apropiación y reconocimiento de su trascendencia a través del tiempo. En este sentido se considera necesario el desarrollo de estrategias que contribuyan a la vinculación de la cuidad al río Magdalena, además de la implementación de propuestas de renovación urbana en la ronda hídrica con el propósito de destacar su alto potencial paisajístico.

Como nuevo configurador de la forma urbana se reconoce el papel que ha desempeñado hasta la actualidad la vía del tren, en este eje de igual manera conviene adelantar intervenciones innovadoras en el espacio público como articulador de la masa edificada, para además contribuir a la protección, recuperación, conservación, revitalización de sus valores patrimoniales, ambientales, urbanos, arquitectónicos, simbólicos e inmateriales con el propósito de preservar el Centro Histórico de Honda como un bien colectivo, sostenible y competitivo. 


\section{Bibliografía}

ARCHIVO GENERAL DE LA NACIÓN. (1741). Fondo Miscelánea, Tomo CVIII.

ARCHIVO GENERAL DE LA NACIÓN. (s.f.). AGN, Fondo Hospitales y Cementerios, Torno III, folios 55-58. .

AZKARATE, A., \& AZPEITIA, A. (2016). Paisajes Urbanos Históricos: ¿Paradigma o subterfugio? En Alla ricerca di un passato complesso. Contributi in onore di Gian Pietro Brogiolo per il suo settantesimo compleanno (págs. 307-326). Zagreb-Motovun: Universidad de Zagreb.

BANCO DE LA REPÚBLICA; VELANDIA. (1999). Cartografía histórica del Alto Magdalena Honda, Girardot y Neiva. Bogotá: Cartoprint Ltda.

COLMENARES, G. (1972). Historia económica y social de Colombia. Cali: Universidad del Valle - División de Humanidades.

CONCEJO MUNICIPAL DE HONDA. (13 de Julio de 2004). Plan Básico de Ordenamiento Territorial. Honda, Tolima, Colombia.

DE SOLA, I. (1967). Contribución al estudio de los planos de Caracas. Caracas: Ediciones del Cuatricentenario.

DUFFO, E. B. (Junio de 2013). Red cultural del Banco de la República en Colombia. El Río Magdalena: Escenario primordial de la patria. Revista Credencial, colección: credencial Historia No. 282. Bogotá. Obtenido de http://www.banrepcultural.org/blaavirtual/revistas/credencial/junio-2013/elrío-magdalena

FLOREZ DE OCARIZ, J. (1674). Libro Primero de las Genealogías del Nuevo Reino de Granada. Madrid: Real Capilla de su Majestad.

GUZMÁN, A. (2002). La ciudad del río . Bogotá : Universidad Nacional de Colombia.

KOSTOF, S. (2005). The city assembled: The elements of urban form through history. Nueva York: Thames y Hudson.

MINISTERIO DE CULTURA. (3 de Febrero de 2017). Resolución número 0217 de 2017, por la cual se aprueba el Plan Especial de Manejo y Protección (PEMP) del casco urbano (Centro Histórico) de Honda (Tolima) y su zona de influencia, declarado monumento nacional (hoy Bien de Interés Cultural del ámbito Naci. Bogotá, D.C., Colombia.

MORRIS, A. (2011). Historia de la forma urbana. Desde sus orígenes hasta la Revolución Industrial. Barcelona: Gustavo Gili.

OCAMPO, J. (1984). Historia básica de Colombia. Bogotá: Plaza \& Janés Editores de Colombia Ltda.

OSPINA-TASCÓN, J. J. (2014). Las Ramblas de Barcelona: Una aportación al estudio de ciudades mediterráneas. La Salle. Universitat Ramón Llull. Tesis doctoral, Barcelona.

PARDO, C., ORTíZ, D., MARTínEZ, C., ENCISO, M., PEREZ, C., PACHÓN, J., . . VALDERRAMA, E. (2007). Manual de historia del Tolima. Ibagué: Atlas impresores Itda.

PRIETO, E. (2009). Tesis de maestría. Centro histórico de Honda: puesta en valor e inserción en el siglo XXI. Refuncionalización. Centro de manzana como propuesta de actuación para su revitalización. Pontificia Universidad Javeriana, Bogotá D.C.

ROSSI, A. (2015). La arquitectura de la ciudad. Barcelona: Gustavo Gili.

URTEAGA, L. (1980). Miseria, miasmas y microbios. Las topografías médicas y el estudio del medio ambiente en el siglo XIX. (Vol. I). Barcelona: Cuadernos Críticos de Geografía Humana. 
URUEÑA, J. M. (2002). La ordenación de los espacios fluviales en las ciudades. En P. de la Cal, \& F. Pellicer, Ríos y ciudades. Aportaciones para la recuperación de los ríos y riberas de Zaragoza (págs. 45-63). Zaragoza: Institución Fernando el Católico.

VELANDIA, R. (1989). La Villa de San Bartolomé de Honda. Bogotá: Cámara de Comercio.

WHITEHEAD, P., SMITH, S., \& WADE, A. (2011). Water, Life and Civilisation. Climate, Environment and Society in the Jordan Valley. Cambridge: Cambridge University Press.

ZAMBRANO, F., \& BernARD, O. (1993). Ciudad y Territorio. Proceso de Poblamiento en Colombia. : Bogotá: Academia de Historia de Bogotá - Fundación de Estudios Hisi6ricos Misi6n Colombia - Instituto Francés de Estudios Andinos.

ZUSMAN, P., HAESBAERT, R., \& CASTRO H. Y ADAMO, S. (2011). Geografías culturales: aproximaciones, intersecciones y desafíos. Buenos Aires: Editorial de la Facultad de Filosofía y Letras-UBA. 